tuberculous mycobacterial infection. In total, 13 patients (31\%) were diagnosed with cancer. Extra-thoracic lymphadenopathy documented by CTwas present in $26(53 \%)$ of patients, including in seven cases of lymphoma and in all cases of Castleman's disease. The diagnosis was established by histopathology in $57 \%$ of cases, by clinical follow-up in 19\% and by microbiology in $7 \%$. USS guided peripheral lymph node biopsy was the preferred biopsy method in 16 cases. Surgical biopsy was performed in seven cases and EBUSTBNA in two cases.

Conclusions Mediastinal lymphadenopathy is common in HIV positive patients undergoing CT scanning of the thorax and can be associated with a wide range of conditions. However, the prevalence of malignancy is high in this setting, emphasising the need for a pathological diagnosis.

\section{P221 DISTAL AIRWAY BACTERIAL COLONISATION IN PATIENTS WITH LUNG CANCER}

doi:10.1136/thx.2010.151068.22

P Agarwal, D J Newberry, J Waller, J Mullings, S Sundaram, P C Russell. Princess Alexandra Hospital, Harlow, UK

Introduction Patients with lung cancer are at higher risk of pulmonary infection due to immunosuppression and impaired function of the natural protective mechanisms which can have an impact on oncological treatment and survival. Aims: To assess the proportion of potentially pathogenic microorganisms (PPM) that colonise the bronchial tree in patients with primary lung cancer.

Methods A bronchoscopic study of 165 patients (101 M and 64 F) aged from 31 to 96 (mean 69years) with confirmed malignancy on bronchial sampling was conducted from January 2005 to July 2010. In all patients, bronchial washings (BW) were performed during bronchoscopy. Obtained BW fluid was subjected to microbiological examination and culture by the semi-quantitative method. A diagnostic level of $>100$ colony forming units (CFU) was set. Computed tomography thorax scans were also assessed for radiological signs of pneumonia.

Results In 27 (16.4\%) of 165 patients, bronchial colonisation of PPM was $>100$ CFU. In 28 patients (17.0\%), the culture of PPM was $<100 \mathrm{CFU}$. The presence of fungi and upper respiratory tract flora was confirmed in $24(14.5 \%)$ and $35(21.2 \%)$ patients, respectively. Mycobacterium Tuberculosis was negative in the 159 patients that had been tested and Mycobacterium Fortuitum was isolated in one patient. Sixteen (9.7\%) patients were colonised with Gram positive PPM. The most frequently isolated PPM was Coliform ( $n=9,5.5 \%)$ followed by Staphylococcus aureus $(\mathrm{n}=8,5 \%)$ and Streptococcus pneumoniae ( $\mathrm{n}=5,3.0 \%$ ). Bronchial colonisation of PPM was highest in patients with small cell lung carcinoma (5/26, 19.2\%) and similar between primary adenocarcinoma $(4 / 30,13.3 \%)$ and squamous cell carcinoma (12/82, 14.6\%). Four multi-drug resistant strains of bacteria $(2.4 \%)$ including MRSA $(n=2)$ were isolated. In five patients $(3.0 \%)$, the bronchial tree was colonised simultaneously by two or more types of PPM. A third (9/27) of patients with PPM also had radiological evidence of pneumonia.

Conclusions Less than $20 \%$ of patients with lung cancer had bronchial colonisation of microorganisms above the assumed diagnostic level. Approximately two-thirds had colonisation with Gram-positive bacteria in their distal airways. Bronchial bacterial colonisation appears to be slightly higher in patients with small cell lung cancer. The identification of potentially pathogenic microorganisms in the distal airways of lung cancer patients, especially at the time of diagnosis, is clinically important before deciding future management strategies. An empirical antibiotics policy would be useful in these patients.

\section{P222 A RETROSPECTIVE STUDY OF DISEASE RECURRENCE POST THORACOTOMY FOR NON-SMALL CELL LUNG CANCER}

doi:10.1136/thx.2010.151068.23

${ }^{1} \mathrm{~J}$ Naqvi, ${ }^{2} \mathrm{~N}$ Navani, ${ }^{2} \mathrm{~S}$ Saeed, ${ }^{3} \mathrm{M}$ Shastry, ${ }^{3} \mathrm{~A}$ Groves, ${ }^{4} \mathrm{P}$ Shaw, ${ }^{5} \mathrm{D}$ Lawrence, ${ }^{5} \mathrm{~S}$ Kolvekar, ${ }^{5} \mathrm{M}$ Hayward, ${ }^{2} \mathrm{~S}$ Janes. ${ }^{1}$ University College London Medical School, London, UK; ${ }^{2}$ Centre for Respiratory Research, University College London, London, UK; ${ }^{3}$ Department of Nuclear Medicine, University College Hospital, London, UK; ${ }^{4}$ Department of Thoracic Radiology, University College Hospital, London, UK; ${ }^{5}$ Department of Cardiothoracic Surgery, The Heart Hospital, London, UK

Background Surgery is the treatment of choice for early stage nonsmall cell lung cancer (NSCLC). However, curative intent is commonly not achieved due to inaccurate clinical staging and disease recurrence. Aim We aimed to determine the incidence of futile thoracotomies (FT) in patients with NSCLC following surgery with curative intent. In addition, we wished to identify prognostic factors that predicted FT. Methods In this analytical retrospective cohort study, thoracotomy cases between October 2003 and September 2008 at a single institution were identified. Confirmed cases of primary NSCLC only were included. A thoracotomy was deemed futile if any one of the following criteria were met: pathologically confirmed N2, N3, or M1 disease, an exploratory thoracotomy, or a thoracotomy in a patient who developed recurrent disease or died within 1 year of surgery. When a PET scan was performed, the SUVmax of the primary tumour was reported by a radiologist blinded to the clinical information. Case notes and hospital systems were interrogated for evidence of recurrence and survival. Statistical analysis was performed with STATA version 10 for Windows.

Results We identified 171 consecutive patients with NSCLC who underwent lung resection with curative intent. 105 (61\%) were male and mean age at the time of surgery was 66years. 134 (78\%) had lobectomy, 8 bi-lobectomy, 19 pneumonectomy and 10 sub-lobar resection (segmentectomy or wedge resection). Overall $46(27 \%)$ underwent FT. Nine patients (5.2\%) had clinically unsuspected N2 disease at pathological staging. An SUVmax of the primary tumour greater than 8 was associated with an increased risk of FT (RR 2.35 $(p=0.03))$ (Abstract P222 Table 1). The presence of lymphovascular invasion was also associated with a increased risk of FT (RR 1.71 $(p=0.04))$. Those with a primary tumour greater than or equal to $3 \mathrm{~cm}$ in size had a RR of $1.91(\mathrm{p}=0.02)$ of FT.

Abstract P222 Table 1 Risk factors for futile thoracotomy

\begin{tabular}{|c|c|c|c|c|}
\hline & \multicolumn{2}{|c|}{ Futile thoracotomy } & \multirow{2}{*}{$\begin{array}{l}\text { Number of } \\
\text { patients }\end{array}$} & \multirow[b]{2}{*}{ p-Value } \\
\hline & Yes & No & & \\
\hline \multicolumn{5}{|l|}{ SUVmax* } \\
\hline$\geq 8$ & 23 & 39 & 100 & 0.025 \\
\hline$<8$ & 6 & 32 & & \\
\hline \multicolumn{5}{|c|}{ Vascular invasion } \\
\hline Yes & 25 & 45 & 171 & 0.036 \\
\hline No & 21 & 80 & & \\
\hline \multicolumn{5}{|c|}{ Adenocarcinoma } \\
\hline Yes & 22 & 63 & 171 & 0.863 \\
\hline No & 24 & 62 & & \\
\hline \multicolumn{5}{|c|}{ Tumour size $\dagger$} \\
\hline$\geq 3 \mathrm{~cm}$ & 32 & 57 & 158 & 0.021 \\
\hline$<3 \mathrm{~cm}$ & 13 & 56 & & \\
\hline \multicolumn{5}{|c|}{ Sub-lobar resection } \\
\hline Yes & 2 & 8 & 171 & 1.000 \\
\hline No & 44 & 117 & & \\
\hline \multicolumn{5}{|l|}{ Gender } \\
\hline Male & 32 & 73 & 171 & 0.217 \\
\hline Female & 14 & 52 & & \\
\hline
\end{tabular}

*71 patients did not undergo pre-operative PET scan.

†Primary tumour size unavailable in 13 patients. 
Conclusions Between 2003 and 2008, 27\% of patients at our cardiothoracic centre for lung cancer underwent a futile thoracotomy. High SUVmax, the presence of lymphovascular invasion and tumour size $\geq 3 \mathrm{~cm}$ are predictors of FT. Future, prospective studies employing adjuvant chemotherapy in these patient groups are warranted.

\section{Organisation of respiratory care P223 ONE BLOOD GAS IS NOT ENOUGH TO ASSESS A PATIENT FOR LTOT-HOW TO KISS GOODBYE TO CIRCA £10 MILLION IN ENGLAND}

doi:10.1136/thx.2010.151068.24

${ }^{1} \mathrm{C}$ Loutsios, ${ }^{2} \mathrm{G}$ Logan, ${ }^{2} \mathrm{C}$ Deeming, ${ }^{1} \mathrm{D}$ Powrie, ${ }^{1} \mathrm{~A}$ Davison. ${ }^{1}$ Southend University Hospital, Southend on Sea, UK; ${ }^{2}$ South East Essex PCT, Southend on Sea, UK

It is recommended in the recent NICE Clinical Guidelines on COPD (June 2010) that stable patients should be offered LTOT if the $\mathrm{PaO}_{2}$ $<7.3 \mathrm{kPa}$ or $>7.3$ and $<8 \mathrm{kPa}$ with associated features; assessment should be made by measuring arterial blood gases on two occasions at least 3 weeks apart in confirmed stable COPD with optimum management. This was the criteria for entry in the MRC and NOTT LTOT trials. This is currently our practice. It has also been recently suggested as part of the COPD National Strategy that only one measurement of blood gases may be necessary. The annual spend on tariffs including LTOT in England in 2006 was $£ 35500000.38$ patients were started on LTOT by the South East Essex Oxygen Service in 1 year from March 2009. In addition 11 stable COPD patients had a blood gas measurement in respiratory outpatients and had a $\mathrm{PaO}_{2}<7.3 \mathrm{kPa}$ (Mean $6.79 \mathrm{SD} 0.4$ ) and when repeated by the oxygen team was above $7.3 \mathrm{kPa}$. These patients therefore did not meet the criteria for LTOT. One patient subsequently did meet the criteria within the year. This suggests that at least an extra $28 \%$ of patients would have been prescribed LTOT if only one initial blood gas below $7.3 \mathrm{kPa}$ was used to assess for eligibility for LTOT. This could produce an extra spend of approximately $£ 10$ million on LTOT if extrapolated across the whole of England. These results suggest that there is considerable variability in $\mathrm{PaO}_{2}$ in hypoxic patients over time. These results also support the current NICE Clinical Guideline which recommends two measurements of arterial blood gases at least 3 weeks apart should be made before prescribing oxygen. This was the evidence base for starting LTOT in randomised controlled trials.

\section{P224 SCREENING OF CORONARY CARE INPATIENTS WITH SPIROMETRY TO DETECT EARLY OBSTRUCTIVE AIRWAYS DEFECTS}

doi:10.1136/thx.2010.151068.25

W Alwan, N Stolagiewicz, N Raison, R Saha, P Murray. St Peter's Hospital, Chertsey, UK

Introduction and objectives COPD is the most common chronic lung disease in the developed world yet many patients do not present until they have advanced disease. Screening to identify those with early obstructive airways defects with spirometry may enable earlier treatment and enrolment in smoking cessation programs. Widespread spirometric screening for COPD in the general population is unlikely to be cost-effective. Cardiology inpatients often share similar risk factors to those with COPD; smoking in particular. We hypothesised that screening patients admitted to our coronary care unit would be an effective way of identifying patients at increased risk of developing COPD by using spirometry to detect early obstructive airways defects.

Methods Patients admitted to a coronary care unit at a district general hospital were selected for spirometric assessment. Medically unstable individuals, deemed as those with a modified early warning (MEWS) score of 2 or more were excluded. Forced volume capacity (FVC) and Forced expiratory volume in one second $\left(\mathrm{FEV}_{1}\right)$ were calculated using a Vitalograph alpha spirometer. The GOLD (Global initiative for Chronic Obstructive Lung Disease) criteria were used to categorise patients according to COPD severity. Those who were found to have airway obstruction were offered repeat testing following discharge.

Results 20 patients were in the initial study population. Four patients were excluded-three because of poor technique and one who had pre-existing COPD. No other patients had any formal diagnosis of respiratory disease. Of the 16 patients, 10 (62.5\%) had objective airways obstruction; $6(37.5 \%)$ patients had GOLD stage I, $3(18.8 \%)$ patients GOLD stage II and $1(6.3 \%)$ patient had GOLD stage 3 disease. Of these 10 patients, seven were smokers or exsmokers. Amongst patients with known ischaemic heart disease, $69.2 \%$ had a degree of airways obstruction, whilst $77.8 \%$ of patients with a history of smoking had an obstructive picture on spirometry. Conclusion Coronary care unit inpatients represent an effective target population to screen for potential obstructive airways disease. Identifying patients with ischaemic heart disease and/or a smoking history will allow patients to be risk-stratified further and increase the sensitivity of spirometry. Our study compares favourably with other methods of identifying high risk groups for screening.

Abstract P224 Table 1 A table to show various proportion of patients found to have airway obstruction on spirometry

\begin{tabular}{llll}
\hline GOLD stage & $\begin{array}{l}\text { All patients } \\
(\mathbf{n = 1 6})\end{array}$ & $\begin{array}{l}\text { Patients with } \\
\text { IHD }(\mathbf{n}=\mathbf{1 3})\end{array}$ & $\begin{array}{l}\text { Current \& ex } \\
\text { smokers }(\mathbf{n}=\mathbf{9})\end{array}$ \\
\hline Normal & 6 & 4 & 2 \\
1 & 6 & 5 & 4 \\
2 & 3 & 3 & 2 \\
3 & 1 & 1 & 1 \\
$\begin{array}{l}\text { Percentage of patients } \\
\text { with obstrctive disease }\end{array}$ & $62.5 \%$ & $69.2 \%$ & $77.8 \%$ \\
$\begin{array}{l}\text { Percentage of patients } \\
\text { with normal spirometry }\end{array}$ & $37.5 \%$ & $30.8 \%$ & $22.2 \%$ \\
\hline
\end{tabular}

\section{P225 FIRST NATIONAL SURVEY OF THE RESPIRATORY PHYSIOTHERAPY WORKFORCE}

doi:10.1136/thx.2010.151068.26

${ }^{1} \mathrm{C}$ Mikelsons, ${ }^{2} \mathrm{M}$ Buxton. ${ }^{1}$ Royal Free Hospital, London, UK; ${ }^{2} \mathrm{NWLH}$ Trust \& Brent PCT, London, UK

In 2008, the RCP/BTS COPD Audit reviewed the multidisciplinary workforce provided by acute Trusts in managing the care of patients with COPD: the results showed that nationally, the median number of respiratory specialist physiotherapists employed in each hospital was 1 (Abstract P225 Table 1), highlighting that the understanding of the number and speciality level of this workforce is poorly recognised by other professionals. In conjunction with the BTS, and to complement the recently published BTS/ACPRC Physiotherapy Guidelines on the Spontaneously Breathing Adult Medical Patient (2009), a survey of the respiratory physiotherapy workforce was carried out in October 2009. An electronic 